\title{
Derivation of Urban Heat Island for Landsat-8 TIRS Riyadh City (KSA)
}

\author{
Menawer K. Almutairi \\ Department of Social Sciences, Taibah University, Madina, Kingdom of Saudi Arabia \\ Email:mnawer88@hotmail.com
}

Received 14 September 2015; accepted 10 November 2015; published 13 November 2015

Copyright @ 2015 by author and Scientific Research Publishing Inc.

This work is licensed under the Creative Commons Attribution International License (CC BY). http://creativecommons.org/licenses/by/4.0/

(c) (i) Open Access

\section{Abstract}

This paper offers a Derivation of Urban Heat Island (UHI) for Landsat-8 TIR on the application of urban climatology in Riyadh city. GIS and remote sensing are provided to determine the possibility of consolidation across the heat island in Riyadh. The primary aim of this work is deviation in temperature and makes up an urban heat island (UHI). To create the database required for the study, using satellite images in monitoring thermal emission peaks for the surface of the earth (UHI), we used band ten and band eleven that represented the thermal band, which depended to extract the temperature of the surface $\left(\mathrm{TOA}_{\mathrm{r}}\right)$. The first step was Conversion DN to Radiance; the second was Radiance into degrees Kelvin and the third was Convert degrees Kelvin into degrees Celsius. In the final Produced Urban Heat Island (UHI), maps help to find out the thermal peaks clearly that affect urban climatology by elevating the temperature of the (UHI) and (UHI) peaks of the surrounding regions and the extent of its impact on the occupants of nearby countries. The paper concluded by the study area contains 10 Urban Heat Islands (UHI). Its presence has been associated with the types of land-utilization and requires intervention by the municipality of the city to hold the (UHI) and dilute the impact and types of land usage. Most impact is negative including increased energy consumption, elevated emissions of air pollutants and greenhouse gases compromised to human health and impaired water quality.

\section{Keywords}

Urban Climatology, Urban Heat Island, GIS, Remote Sensing, Landsat-8 TIRS

\section{Introduction}

The Urban Heat Island (UHI) effect is a widely studied phenomenon. It has been defined as "the characteristic warmth of a settlement compared with its surroundings [1]. That occurs when rural cooling rates are greater than 
urban cooling rates [2]. As urban areas grow, changes take place in the landscape. Buildings, roads, and other infrastructure, replace open land and vegetation. The climate of the city reflections of environmental heat produced is due to the variation in the distribution of surface temperatures between the ranges of the city and contrasts the characteristics of the flow of thermal radiation, which leads low leakage thermal radiation of the surface into space, because of the accretion of buildings to increase the hotness of the streets. In addition, becoming centers of cities and the urban area interior warmer than its margins in the appearance known as (UHI), where the surface temperature rises clearly around the top of this range thermal temperature drops dimension with it in all directions.

Many urban and suburban areas have elevated temperatures compared to their out-lying rural surroundings; this deviation in temperature is what makes an urban heat island. The annual mean air temperature of a city with one Meg or more people can be $1.8^{\circ} \mathrm{F}$ to $5.4^{\circ} \mathrm{F}\left(1^{\circ} \mathrm{C}\right.$ to $\left.3^{\circ} \mathrm{C}\right)$ warmer than its surroundings [3], the phenomenon of (UHI) emission to the Earth's surface (heat island) in major urban centers. Moreover, unitary of the deviations high-thermal effects human health and bioactivity, which are related to differences spatial surface temperatures in the urban center of Riyadh, as they lead to the heating of the Earth's surface due to the increased potency of global warming which is the most significant global environmental problem. More than 197 international scientific organizations agree that global warming is really rising because of human actions by human activity.

The study directly aimed at deriving urban heat islands through Landsat 8, attempting to detect the whereabouts of the (UHI) as a focus thermal heat which directly affected the city as influential in human life by raising the temperature regions as it was located. It isn't enough to explain the reason heat islands through satellite images without identifying through GIS, so this study is characterized by converting digital satellite images data of the surface temperatures (TIRS) to ISO temperature lines which are able to determine the thermal islands and thermal island peak more effectively. This difference is going to appear during this study later.

Landsat 8 carries two instruments: The Operational Land Imager (OLI) sensor, which includes refined heritage bands, along with three new bands: a deep blue band for coastal/aerosol studies, a short-wave infrared band for cirrus detection [4], and a Quality Assessment band. The Thermal Infrared Sensor (TIRS) sensor provides two thermal bands. These sensors both provide improved signal-to-noise (SNR) radiometric performance quantized over a 12-bit dynamic range. (This translates into 4096 potential gray levels in an image compared with only 256 gray levels in previous 8-bit instruments.) Improved signal to noise performance enables better characterization of land cover state and condition. Products are delivered as 16-bit images (scaled to 55,000 gray levels) [5].

In addition, Landsat 8 carries two push-broom instruments: the Operational Land Imager (OLI), and the Thermal Infrared Sensor (TIRS).The spectral bands of the OLI sensor, while similar to Landsat 7's ETM+ sensor, provide enhancement from prior Landsat instruments, with the addition of two new spectral bands: a deep blue visible channel (band 1) specifically designed for water resources and coastal zone investigation, and a new infrared channel (band 9) for the sensing of cirrus clouds. A new quality assurance band is also included with each data product. It provides information on the presence of features such as clouds, water, and snow. The TIRS instrument collects two spectral bands for the wavelength covered by a single ring on the previous TM and $\mathrm{ETM}+$ sensors [6].

\section{Building Geodatabase}

\subsection{First: Producing Temperature According to Satellite Images}

Using satellite Images in monitoring thermal emission peaks for the surface of the earth (UHI) is considered one of the modern studies specialized in an advantage cause to use. This study had depended on satellite Images; these Images had been using Universal Transverse Mercator Projection (UTM) and coordinate system (WGS 84) [7].

The grooming of the Images passed many important forms in order to be valid for producing thermal composition maps for Riyadh city briefed as follows and shown in Figure 1:

1) Determination satellite images

Riyadh city is located at two different paths for landsat satellite, the first path is $165 / 04300$ and the second path is $166 / 04300$ to be able to mosaic process for both paths, Also this tow Images Dating back to the date of 16 August 2014 and 25 August 2014.

2) Geometric correction of satellite images 


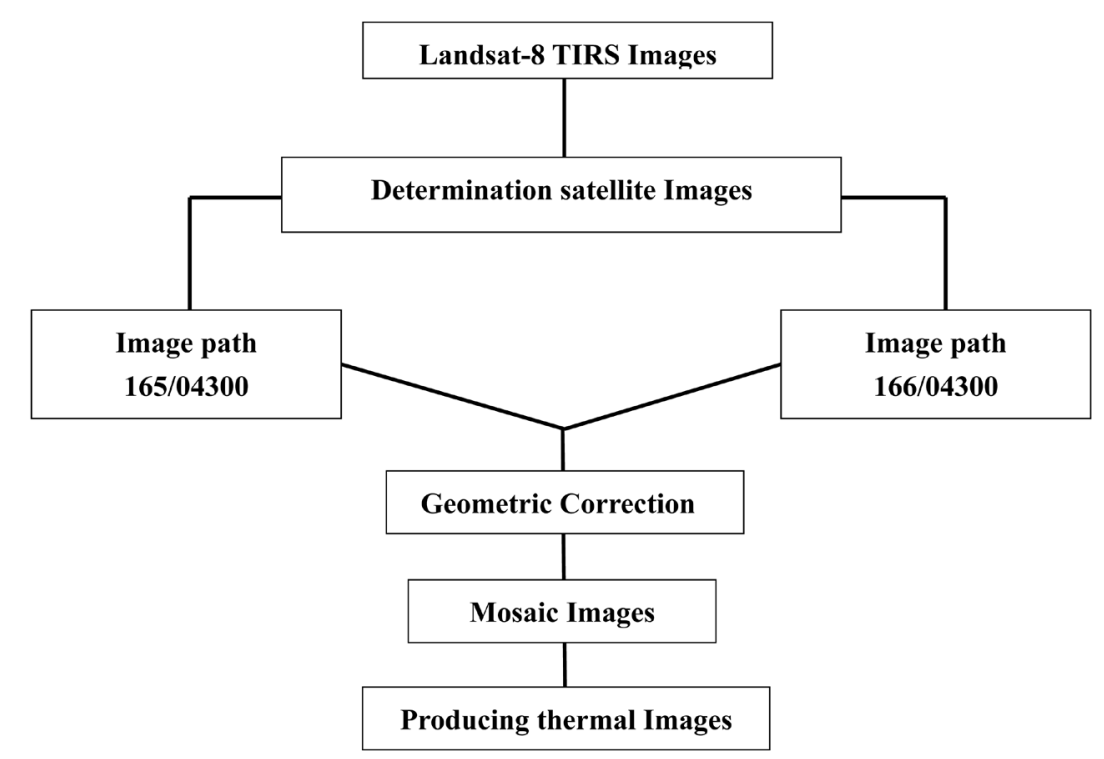

Figure 1. Thermal images producing process. Source researcher.

Evaluation of the results of the geometric correction used a set of checkpoints different from the Ground Control Points (GCPS). Used in the least squares transformation, and using the same polynomial equations as for the GCPS set to determine residuals, and RMS errors for the checkpoints [8], we used image to image rectification for the Images of Landsat and the goal is process correct distortions random by comparison Ground Control Point (GCPs).

3) Mosaic images

MosaicPro streamlines the editing process with various capabilities, allowing the user to select images directly, control that input images are rendered and turns image footprints and other graphics on and off. The user interface of MosaicPro also simplifies the workflow by providing tools in a single [9].

To get complete covering for study area, we used Mosaic Images in ERDAS IMAGINE, there are requirements that needs to be satisfied which is that both of the Images must be rectified and projected with the same projection and must be a mutual region between both Images.

4) Producing thermal images

We import Band tenand Band eleven that represents the thermal band, which analysis depend to extract the temperature of the surface $\left(\mathrm{TOA}_{\mathrm{r}}\right)$ As follows [10]:

a) Reading the metadata: All of the inputs that we need to do this will be in the metadata file. In fact, the inputs that needed to perform this conversion are the same for the entire Landsat 8 images Table 1.

b) Conversion from DN to radiance: The Radiance Multiplier and Radiance Add are used to convert the DN back into radiance. Remember from back in the day, that the equation of a line is $\mathrm{y}=\mathrm{mx}+\mathrm{b}$

- $\mathrm{y}$ is Top of Atmosphere Radiance $\left(\mathrm{TOA}_{\mathrm{r}}\right)$.

- $\mathrm{m}$ is the Radiance Multiplier.

- $\mathrm{x}$ is the raw band.

- $\mathrm{b}$ is the Radiance Add.

c) Convert radiance into degrees Kelvin: From TOAr, we change with temperature in degrees Kelvin. This is where we use the $\mathrm{K} 1$ and $\mathrm{K} 2$ inputs. The equation we will be using subroutines to create is:

$$
\mathrm{K} 2 / n\left(\mathrm{~K} 1 / \mathrm{TOA}_{\mathrm{r}}+1\right)
$$

d) Convert degrees Kelvin into degrees Celsius: we have converted the $\mathrm{TOA}_{\mathrm{r}}$ into degrees Celsius. We need to subtract 273.15 from the degrees Kelvin Figure 2 and Figure 3.

Figure 4 shows in band ten and band eleven Temperature Line two thermal peaks reached. Where the temperature during the cross section of the satellite Image in $41.5^{\circ}$ in the center of the city of Riyadh, and this is normal, as we know that the heat island rises degrees in the center of the city. Moreover, begin to come when the parties because of the factors mentioned above. Such as increasing the paved roads and the attendant increase in uses cars, air conditioner uses heavily, population density and the high numbers of buildings and their assemblage. 
Table 1. Metadata of thermal band of the landsat 8 images.

\begin{tabular}{ccc}
\hline & Band 10 & Band 11 \\
\hline Radiance Multiplier & 0.0003342 & 0.0003342 \\
Radiance Add & 0.1 & 0.1 \\
K1 & 774.89 & 480.89 \\
K2 & 1321.08 & 1201.14 \\
\hline
\end{tabular}

Source: metadata files.

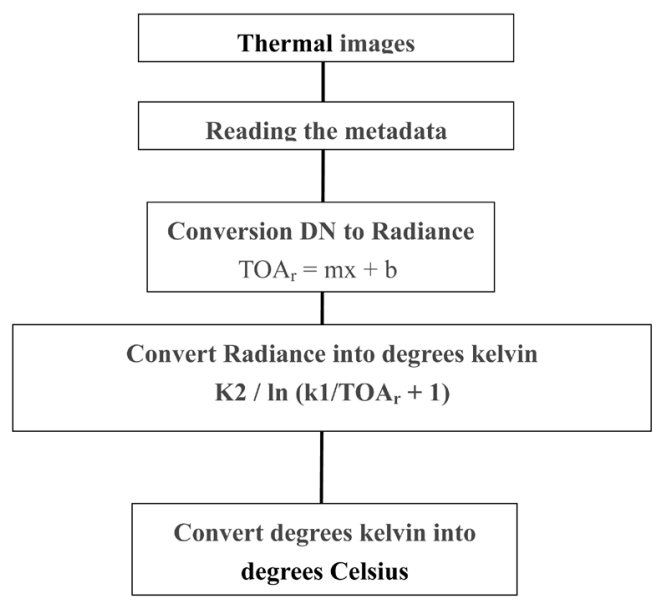

Figure 2. Temperature of the surface producing process. Source researcher.
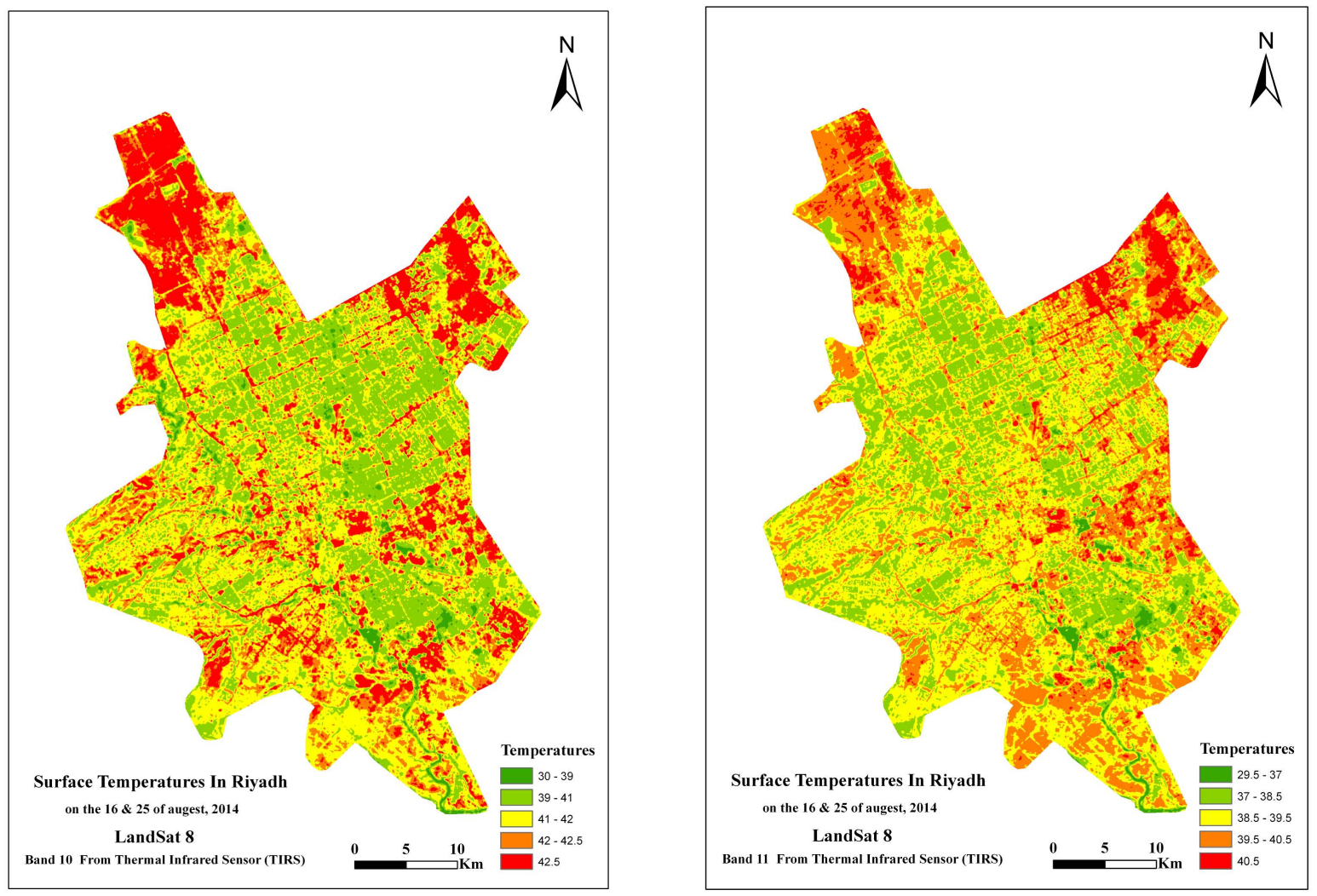

Figure 3. Surface temperatures in Riyadh city. Source researcher. 
On the other hand, low thermal peak existed on the eastern edge of the city affected by the presence of an open area featuring gardens, highlighting the cause of a significant drop in temperatures to $31^{\circ}$.

\subsection{Second: Producing Thermal Maps}

After making the process of production of surface temperature. Urban heat islands maps are produced Figure 5,
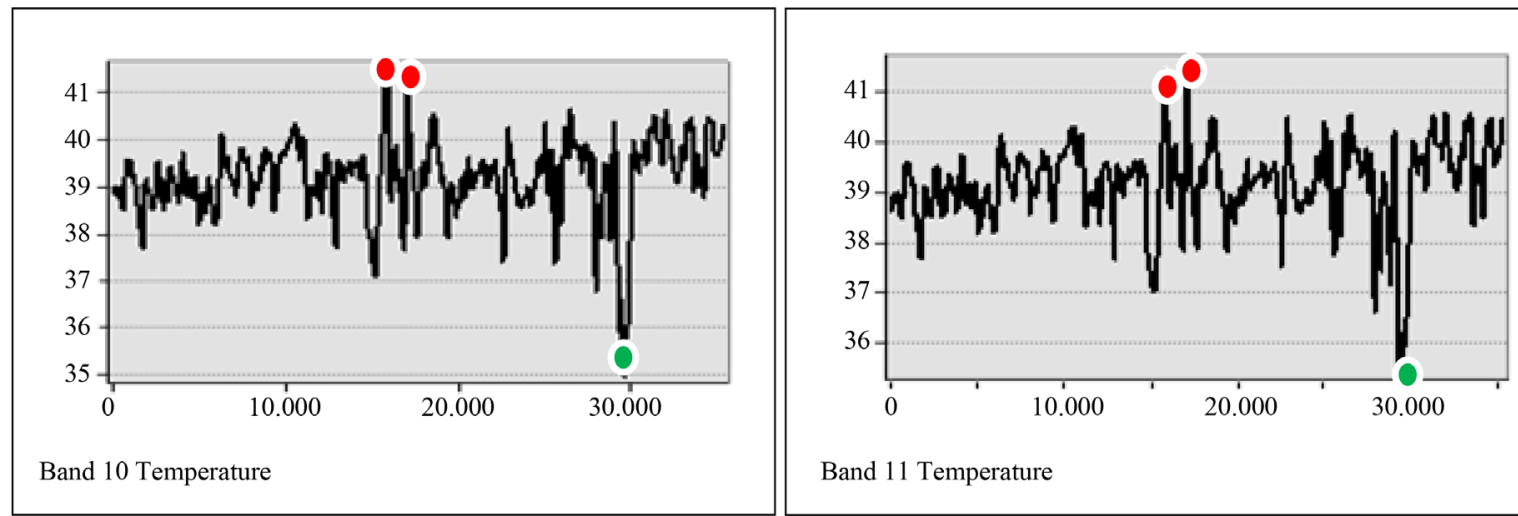

Band 11 Temperature

Figure 4. 3D line sector for temperature. Source researcher.

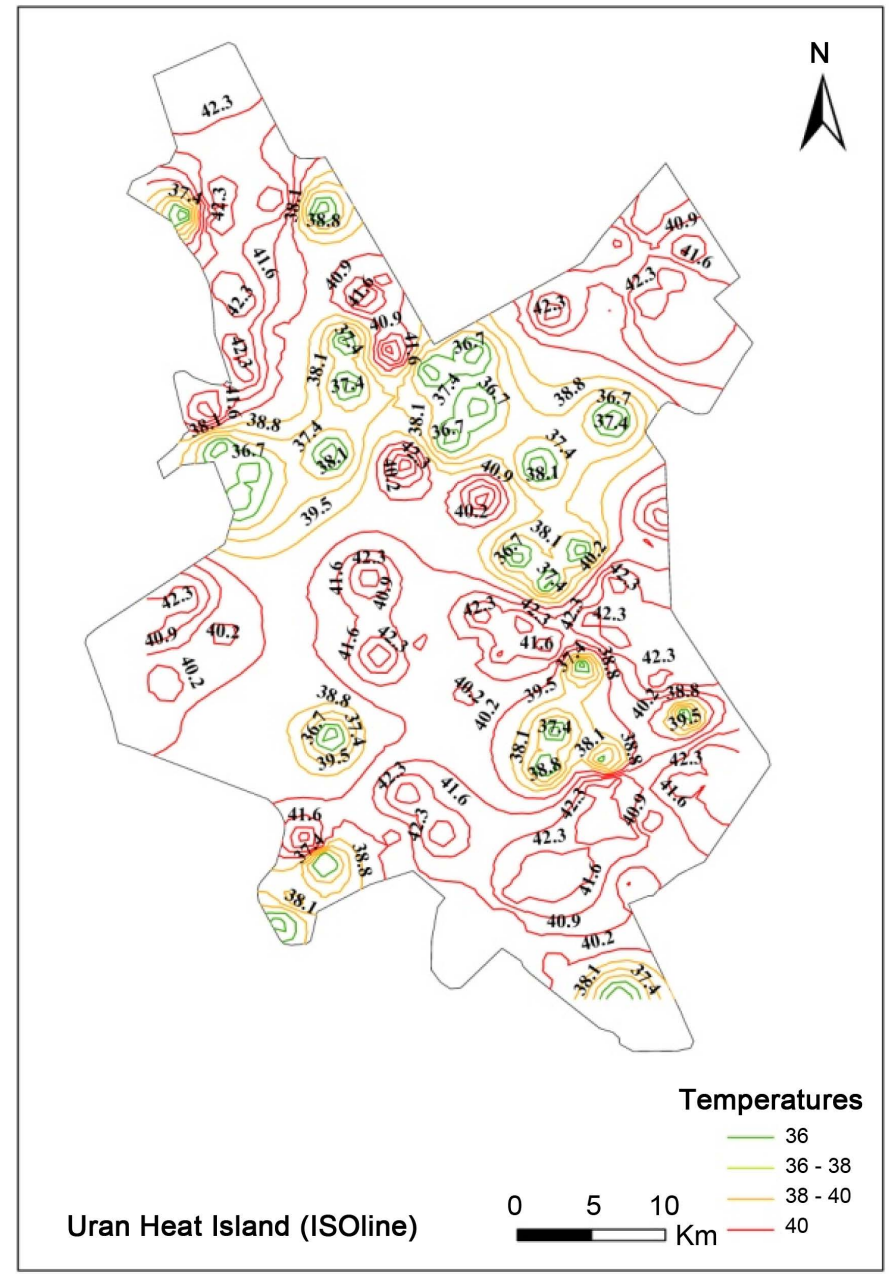

Figure 5. Thermal ISO line of Riyadh city. Source researcher. 
which are formed due to the variation in the distribution of surface temperatures between the ranges of the city and contrast the characteristics of the flow of thermal radiation, which lead low leakage thermal radiation of the surface into space, because of the accumulation of buildings to increase warmth streets, and become centers of cities and the urban area of internal Warmer margins.

In addition, passed the process of producing thermal map stages as follows:

1) Calculate average temperatures percentage at the neighborhood level.

2) Distribution point's average temperatures percentage in the study area covers the full.

3) Establish lines of ISOline ${ }^{1}$ temperatures.

\section{Conclusion}

The study proved the effectiveness of the use of satellite Images Landsat 8 in extracting urban heat island (UHI), GIS integrated with remote sensing helped in determining the (UHI) peaks in Riyadh city. Mainly (UHI) intensity (found difference between the temperature of the city center and the surrounding countryside at night). It can be averaged over different periods (e.g. the season). The daytime (UHI) is also available. The study area contains ten heat islands. There are three (UHI) peaks in the north, which is characterized by being a new urban area of the city tended to grow in this direction. Two (UHI) peaks summit in the eastern study area. One (UHI) peak summits in the west of the study area. Other one heat summits in the southern study area. Four (UHI) peaks summit in the center of the study area. It underlines the depth of concentration in this region and is associated with urban heat island areas and industrial and commercial areas. As in the east, south and center of the study area, some communities are formed as (UHI) in the north and east of the study area. Produce maps of isolines of (UHI) which allow knowing the study area contain 10 heat islands. Its presence has been associated with the kind of land-use and requires intervention by the municipality of the city to control the heat islands and reduce the impact and spaces.

Urban heat island can affect a community's environment and quality of life. The most impact is negative including increased energy consumption, elevated emissions of air pollutants and greenhouse gases compromised to human health and impaired water quality.

\section{References}

[1] Grimmond, S. (2011) London's Urban Climate: Historical and Contemporary Perspectives. City Weathers: Meteorology and Urban Design 1950-2010. Manchester Architecture Research Centre, University of Manchester, Manchester.

[2] Oke, T.R. (2011) Urban Heat Islands. In: Douglas, I., Goode, D., Houck, M. and Wang, R., Eds., The Routledge Handbook of Urban Ecology. Routledge Handbooks, New York.

[3] Akbari, H. (2005) Energy Saving Potentials and Air Quality Benefits of Urban Heat Island Mitigation (PDF) (19 pp, 251K). Lawrence Berkeley National Laboratory, Berkeley.

[4] Gao, B.C. and Kaufman, Y.J. (1995) Selection of the 1.375 Micrometer MODIS Channel for Remote Sensing of Cirrus Clouds and Stratospheric Aerosols from Space. Journal of the Atmospheric Sciences, 52, 4231-4237. http://dx.doi.org/10.1175/1520-0469(1995)052<4231:SOTMCF $>2.0 . C O ; 2$

[5] http://landsat.usgs.gov/landsat8.php

[6] http://landsat.usgs.gov/ldcm_vs_previous.php

[7] Mugnier, C. (2008) Datums and Coordinates Systems: Kingdom of Saudi Arabia. ASPRS Journal, 949-951.

[8] Kardoulas, N.G. (1996) Geometric Correction of SPOT and Landsat Imagery: A Comparison of Map and GPS-Derived Control Points. Photogrammetric Engineering \& Remote Sensing, 62, 1173-1177.

[9] Erdas Imagine Product Feature and Comparisons, Intergraph Corporation. GEO-US-0040C-ENG 01/1, 2014.

[10] http://landsat.usgs.gov/Landsat8_Using_Product.php

${ }^{1} \mathrm{An}$ isoline is simply a generic term for any line on a map that connects points of equal value. 